Article

\title{
Analysis and Diagnosis of Truck Transport Routes in Underground Mines Using Transport Time Data Collected through Bluetooth Beacons and Tablet Computers
}

\author{
Sebeom Park (D) and Yosoon Choi * (D)
}

check for updates

Citation: Park, S.; Choi, Y. Analysis and Diagnosis of Truck Transport Routes in Underground Mines Using Transport Time Data Collected through Bluetooth Beacons and Tablet Computers. Appl. Sci. 2021, 11, 4525. https://doi.org/10.3390/app11104525

Academic Editor: António Vieira

Received: 28 April 2021

Accepted: 13 May 2021

Published: 15 May 2021

Publisher's Note: MDPI stays neutral with regard to jurisdictional claims in published maps and institutional affiliations.

Copyright: (c) 2021 by the authors. Licensee MDPI, Basel, Switzerland. This article is an open access article distributed under the terms and conditions of the Creative Commons Attribution (CC BY) license (https:/ / creativecommons.org/licenses/by/ $4.0 /)$.
Department of Energy Resources Engineering, Pukyong National University, Busan 48513, Korea; sebumi1v@gmail.com

* Correspondence: energy@pknu.ac.kr; Tel.: +82-51-629-6562; Fax: +82-51-629-6553

\begin{abstract}
In this study, we developed a system to collect and analyze log data related to truck travel times in underground mines using Bluetooth beacons and tablet computers. When a signal from beacons installed at a major underground mine is received by a truck-mounted tablet computer, the beacon information is collected and uploaded to a cloud server. A data processing program integrates the uploaded log data files into a single file, calculating the statistical values for each section of the transport route. The developed system was applied to a limestone underground mine located in Jeongseon, Korea, to diagnose and analyze the transport routes in the study area. As a result of this analysis, it was possible to select sections in which the truck transport time was stable and sections in which it was unstable. Consequently, the transport route could be classified into four types based on the distribution and fluctuations in the truck transport time data. Moreover, it was possible to analyze the causes of the stable and unstable sections through production logs and field staff interviews. The developed system could be used as a tool to improve transport operations by diagnosing and analyzing the truck transport routes of a mine.
\end{abstract}

Keywords: underground mine; transport time; Bluetooth beacon; tablet computer; smart mining

\section{Introduction}

Innovative technologies at the forefront of the fourth industrial revolution include artificial intelligence (AI), drones, the Internet of Things (IoT), 3D printing, robotics, autonomous driving, and big data. These technologies are spreading throughout the industry to improve its productivity and efficiency and are causing major social and economic changes [1,2]. As the fourth industrial revolution has begun in the mining industry, significant changes are taking place in the traditional mining value chain-from mineral exploration to exploitation, processing, and sales [3]. Smart mining is at the center of this change. Smart mining refers to the introduction of cutting-edge information and communication technology (ICT) such as the IoT, big data, mobile, AI, and augmented reality (AR), preparing the way for the fourth industrial revolution and new climate change regimes, and to realize eco-friendly, high-efficiency, low-cost, and disaster-free mining sites. Smart mining technology consists of hardware $(\mathrm{H} / \mathrm{W})$ technology, such as data acquisition sensors, wired and wireless communications devices, power supplies, control devices, data processing servers, and software $(S / W)$ technology that can analyze and effectively visualize collected field data [4,5]. Moreover, an ideal smart mine can be built by gradually utilizing IoT technology [6].

The IoT refers to a virtual world in which all types of objects existing in the world can be connected to each other in various ways to provide new services. In the mining industry, the IoT can be particularly useful for workers' safety management, field environment monitoring, work efficiency improvement, and transport system improvement; consequently, related technologies have been developed by various researchers [7]. Regarding the safety 
management of mining workers, technologies have been developed that detect changes in the environment around workers by attaching various sensors, which can detect a worker's location, movement, heart rate, temperature, humidity, and the gas concentration, to helmets [8-11]. Solutions have also been developed that allow workers to directly identify environmental changes using wearable devices such as smart glasses or smartwatches [12]. Moreover, a number of sensors with wireless communication functionality have been used to evaluate a mine's overall performance and secure stability, as well as acquire data that are difficult to obtain directly from people [13-16].

Recently, attempts have been made to improve the transportation system by managing the safety of mines and improving work efficiency using beacons based on Bluetooth low-energy technology. Kiziroglou et al. [17] used Bluetooth beacons for monitoring the transport of ore or waste. Radinovic and Kim [18] studied the possibility of using Bluetooth wireless technology for tracking and mapping of personnel and equipment in underground mines. Additionally, they analyzed the costs associated with installing these systems in underground mines and evaluated the performance of the system [18]. Wu et al. [19] designed a Bluetooth-based underground mine-monitoring system to detect changes in the gas concentration in real time and transmit measurement data through a wireless communication network. Beak and Choi [20] proposed a Bluetooth beaconbased proximity warning system that could prevent collisions in underground mines. A smartphone installed in a vehicle received signals from Bluetooth beacons attached to the operator or equipment, providing a step-by-step response depending on the received signal strength. Jung and Choi [21] measured and analyzed the transport time of trucks dispatched to the transport system of an underground mine. Field experiments demonstrated that Bluetooth beacon systems could conveniently and accurately measure truck transport times. Beak et al. [22] developed a Bluetooth beacon-based underground navigation system that could display optimum transport routes and truck locations in underground mines on a mobile device. Whenever the system recognized a signal from a Bluetooth beacon, it provided the truck driver with information about the current location and route via the mobile device. Park and Choi [23] developed a mine production management application that could support efficient underground mine loading-haulage system operations using Bluetooth beacons and tablet computers. The application included a navigation function that output truck location information, a proximity warning function that helped prevent collisions between vehicles, and a function that automatically created a production log. Although some studies have been conducted to use Bluetooth technology in the mining industry, little attention has been paid to diagnose the operational status of truck transport systems in mines by analyzing data acquired from Bluetooth beacons.

The purpose of this study was to develop a system that can collect and analyze log data related to truck transport times in underground mines using Bluetooth beacons and tablet computers. First, a limestone underground mine in Korea was selected as the study area, and log data related to truck transport times were collected by applying the developed system. Next, using the log data uploaded to the cloud server over a certain period, the truck transport routes in the study area were diagnosed and analyzed; the results are presented herein.

\section{Study Area}

In this study, a Choongmoo Chemical Co., Ltd. underground limestone mine $\left(37^{\circ} 31^{\prime} 92.31^{\prime \prime} \mathrm{N}\right.$, $128^{\circ} 72^{\prime} 52.44^{\prime \prime}$ E) located in Jeongseon-gun, Gangwon-do, Korea was selected as the research area (Figure 1) for the development of a system that could collect and analyze log data related to truck transport times and diagnose and analyze the truck transport routes through a field application experiment. 


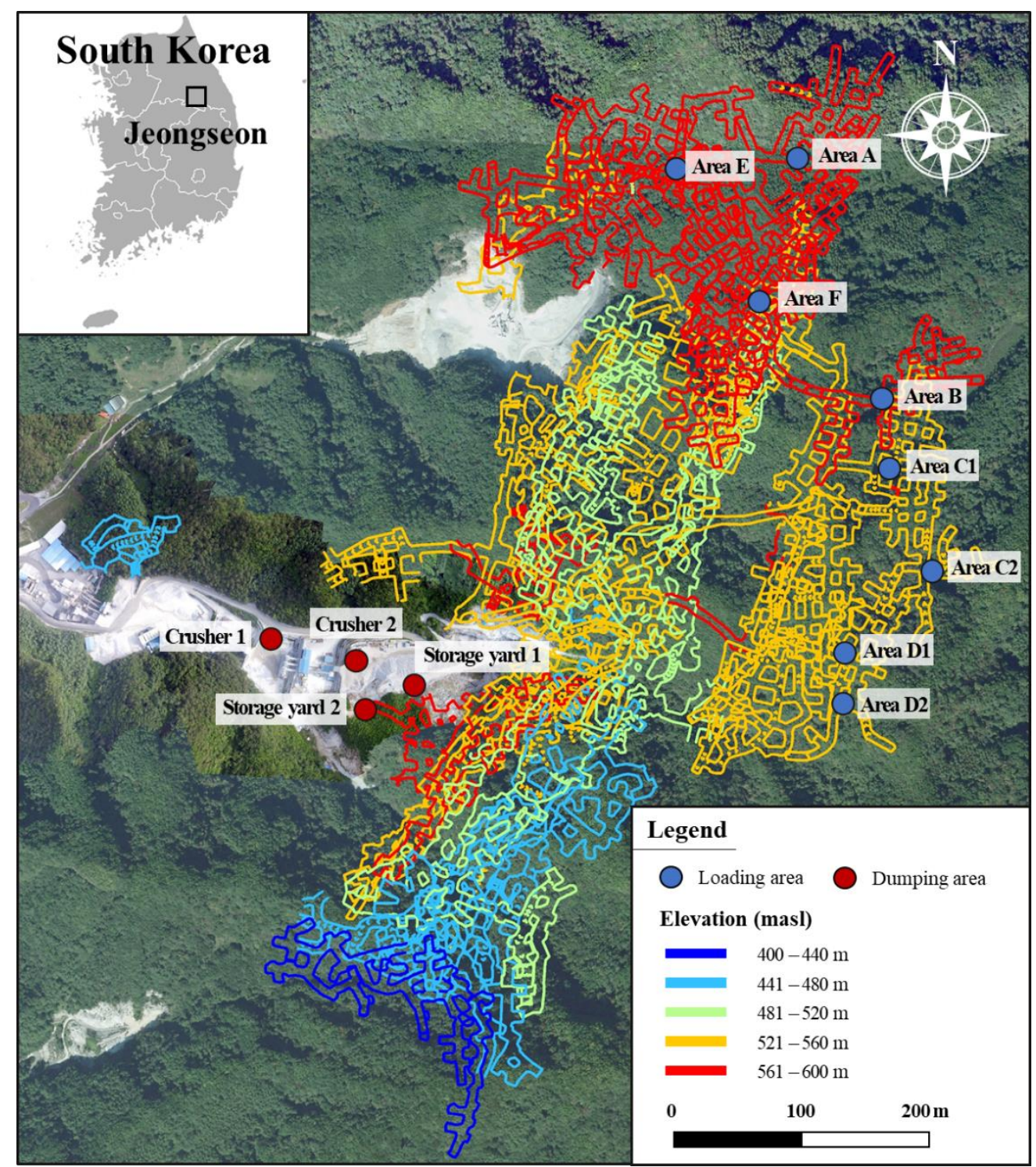

Figure 1. Map of the study area (Choongmoo Chemical Co., Ltd. underground limestone mine, Jeongsun-gun, Gangwon-do, Korea) showing the loading areas and dumping areas.

The limestone was mined using the room and pillar method, the main adit (entrance) was in the direction of the N20E strike, and the crosscut was horizontal. The ore bodies located at the bottom were connected using lamps, leading to each level. The ratio of the room and the pillar was maintained at approximately 1:1, and the size of the room was $12 \mathrm{~m}$ wide and $8 \mathrm{~m}$ high. The mining process proceeded in the following order: drilling, blasting, loading, haulage, and roof control (rock bolt and wire mesh). Blasting was performed an average of eight times a day using ammonium nitrate fuel oil and electric detonators, producing approximately 5000 tons of limestone per day. Moreover, the limestone produced was loaded on a dump truck ( 24 tons) and transported to a crusher located outside the mine at a distance of approximately $1-1.5 \mathrm{~km}$.

To analyze the loading-haulage system in the study area and introduce a system that could collect data related to truck transport times, environmental surveys inside and outside the mine and 3D drawing analyses were conducted. High humidity was observed in all routes in the mine constituting the loading-haulage system, and groundwater leakage was observed at some points. The concentration of fine dust in the mine was also high because of the scattering dust during the loading and transportation of the limestone. 
Moreover, irregularities were observed on the walls of the mine, although the bottom surface of the transport route remained relatively flat.

An analysis of the mined limestone transportation route was conducted through direct investigation - performed by boarding trucks dispatched to the production operation - and the analysis of images using drones and 3D drawings. As a result of the analysis, eight loading areas and four dumping areas in the study area were operational, and three loaders and 10 trucks were dispatched to the loading-haulage operations to produce limestone. Limestone transported out of the mine was sorted visually by utilizing rock color differences, and the final dumping point was determined.

\section{Methods}

\subsection{Development of Log Data Collection System Related to Truck Transport Time}

Bluetooth beacons and tablet computers were used to collect log data related to truck transport times, and the collected log data were uploaded to the cloud server and managed (Figure 2). A tablet computer mounted on the truck received signals from Bluetooth beacons installed on major routes inside and outside the mine where the haulage was performed. The tablet computer stored the information (beacon ID, location, and time) received from the Bluetooth beacon in its built-in memory. Log data stored during haulage operations were uploaded to a cloud server in a wireless communication area located outside the mine, which then stored and managed the data transmitted to it from tablet computers installed on multiple trucks.

The Bluetooth beacons and tablet computers used to collect log data related to truck transport times should operate reliably even in harsh environments with high humidity and dusty underground mines. Bluetooth beacons and tablet computers are easy to maintain and manage, have good durability and after-service (A/S), and can be purchased easily in the market. Moreover, it is important that Bluetooth beacons have a minimum specified signal strength because tunnel conditions are not constant at all points in the mine. In this study, Beacon i3 (Hyunseung; Seoul, Korea) was selected, being convenient for controlling the signal strength and transmission period of beacons, having a long battery life, and including dustproof and waterproof design features. Beacon i3 proved its reliability in a study conducted by Park and Choi [20]. For detailed specifications, please refer to the study mentioned above. Tablet computers that can receive signals from Bluetooth beacons and store $\log$ data are available in various price ranges; they should have sufficient storage capacity, the latest Wi-Fi and Bluetooth specifications, be based on the Android operating system version, and be easy to use. In this study, Galaxy Tab A 8.0 (Samsung; Seoul, Korea) was selected, and the detailed specifications are shown in Table 1. Moreover, the EAP110-Outdoor, which can cover a wide range and provide sufficient communication speed, was selected for the Wi-Fi access point (AP) to establish a wireless communication area in the study area. The product is equipped with waterproofing and dustproofing features; thus, it can be installed outdoors, providing a stable wireless communication range of approximately $200 \mathrm{~m}$ (Table 2). 


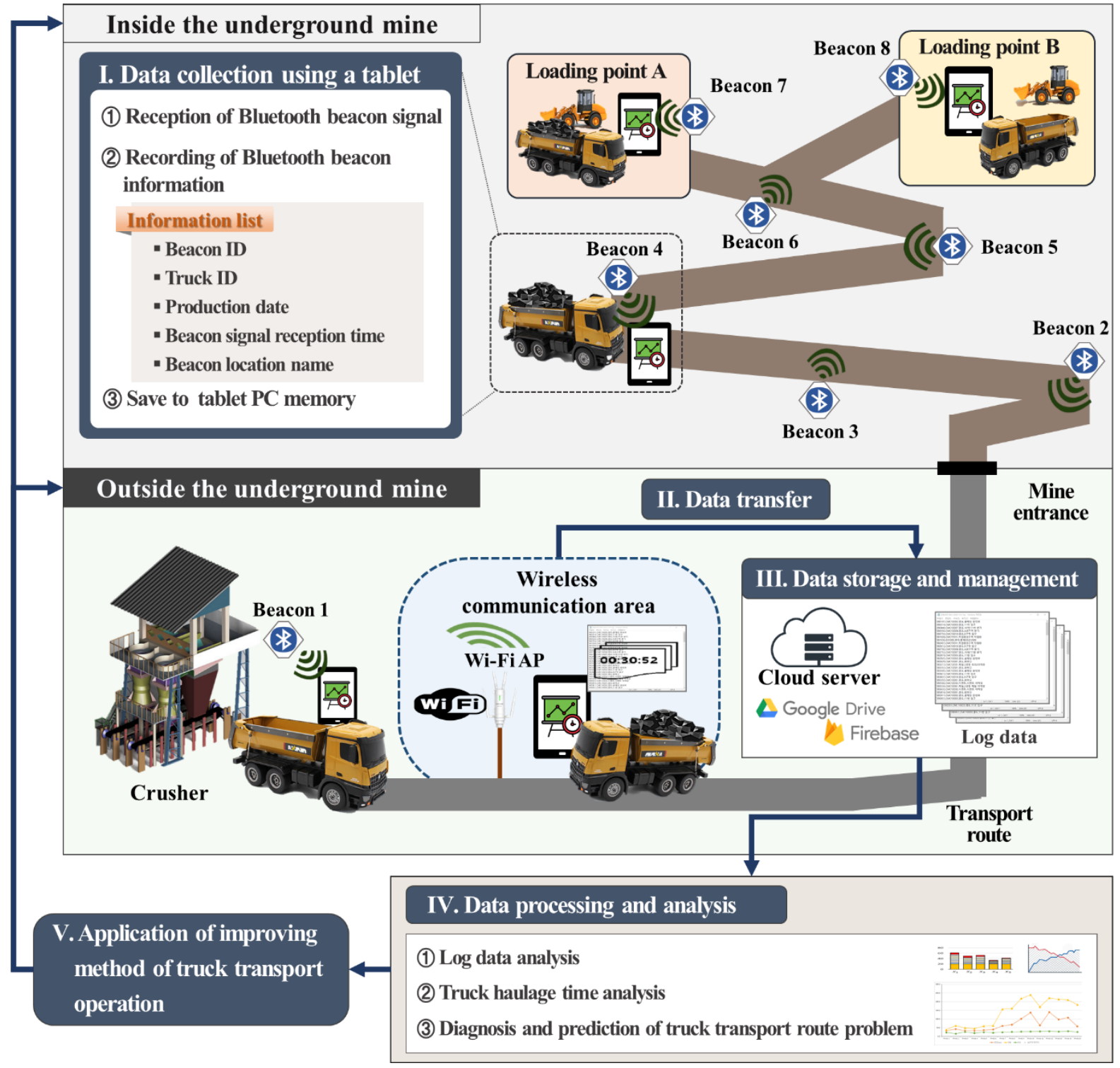

Figure 2. Conceptual diagram showing the operating principle of the log data collection system related to truck transport times using Bluetooth beacons and tablet computers.

Table 1. Specifications of the Galaxy Tab A 8.0 (Samsung; Seoul, Korea) used to receive Bluetooth beacon signals and store log data.

\begin{tabular}{ccc}
\hline & \multicolumn{2}{c}{ Specifications } \\
\hline \multirow{2}{*}{ General } & Model & Galaxy Tab A 8.0 (2019) Wi-Fi \\
\cline { 2 - 3 } & Battery capacity (mAh) & 5100 \\
\cline { 2 - 3 } Hardware & Processor & 2 GHz octa-core \\
\cline { 2 - 3 } & RAM & 2 GB \\
\cline { 2 - 3 } & Expandable storage & Yes (microSD, up to 512 GB) \\
\hline Software & Operating system & Android 9 Pie \\
\hline \multirow{2}{*}{ Connectivity } & Wi-Fi standards supported & $802.11 \mathrm{a} / \mathrm{b} / \mathrm{g} / \mathrm{n}$ \\
\cline { 2 - 3 } & Bluetooth version & 4.20 \\
\hline
\end{tabular}


Table 2. Specifications of the EAP110-Outdoor (TP-Link; Shenzhen, China) used to establish a wireless communication area in the study area.

\begin{tabular}{|c|c|c|}
\hline \multicolumn{3}{|c|}{ Specifications } \\
\hline \multirow{5}{*}{ Wireless } & Wireless frequency bands & 2.4 GHz Single-Band \\
\hline & Number of antennas & 2 \\
\hline & WLAN mode & Wi-Fi $4(8,0211$ n) \\
\hline & Transmit power & $27 \mathrm{dBm}$ \\
\hline & Antenna placement & External (unspecified connection type) \\
\hline \multirow{2}{*}{ Security } & Guest network support & Yes \\
\hline & Wireless security & WEP, WEP 128, WEP 64, WPA, WPA2 \\
\hline \multirow{2}{*}{ Electrical } & Power consumption & $3.12 \mathrm{~W}$ \\
\hline & Operating temperature & 22 to $149^{\circ} \mathrm{F} /-30$ to $65^{\circ} \mathrm{C}$ \\
\hline \multirow{3}{*}{ Environmental } & Storage temperature & -40 to $158^{\circ} \mathrm{F} /-40$ to $70^{\circ} \mathrm{C}$ \\
\hline & Operating humidity & 10 to $90 \%$ \\
\hline & Storage humidity & 5 to $90 \%$ \\
\hline
\end{tabular}

The installation points of the Bluetooth beacons were selected based on the results of an analysis of the loading-haulage system, aerial photography, 3D drawings, and production logs. As a result, it was found that installing beacons in 8 loading areas, 4 dumping areas, and 10 major transport routes would be a suitable choice (Figure 3a). Figure $3 \mathrm{~b}$ shows a schematic of the truck transport route. The locations and altitudes of Bluetooth beacons installed in the study area are also illustrated. Using the difference in altitude between the origin and destination, it is possible to determine whether the truck has traveled uphill or downhill transport routes.

Considering the high humidity and dusty underground mines, the Bluetooth beacons installed inside and outside the mine were installed after minimizing the risk of corrosion and erosion (Figure $4 \mathrm{a}, \mathrm{b}$ ) - that is, when assembling the Bluetooth beacons, rubber packing was used to prevent moisture and dust from penetrating the device. Moreover, when installing the beacons, the risk of corrosion and erosion was further minimized by using plastic bags. At points where the beacon signal was bad due to irregular tunnel specifications and tunnel wall irregularities, the beacon installation angle was adjusted using a bracket. The signal strength of all installed Bluetooth beacons was set to $4 \mathrm{dBM}$ (maximum strength), and the signal transmission period was set to $200 \mathrm{~ms}$ (a polling average of 5 times per second). To build wireless communication zones, Wi-Fi APs were installed in the truck parking area before or after production, allowing log data to be sent to the cloud server at least once a day (Figure 4c). Tablet computers were installed on the windshields or dashboards of 10 trucks used in production (to increase the signal reception rate of beacons). To prevent the tablet computers from shutting down due to battery shortages during production, they were connected to charging cables at all times to ensure continuous charging (Figure $4 \mathrm{~d}$ ). Note that the transport time of a truck is measured under the same conditions, regardless of whether the truck is loaded. 

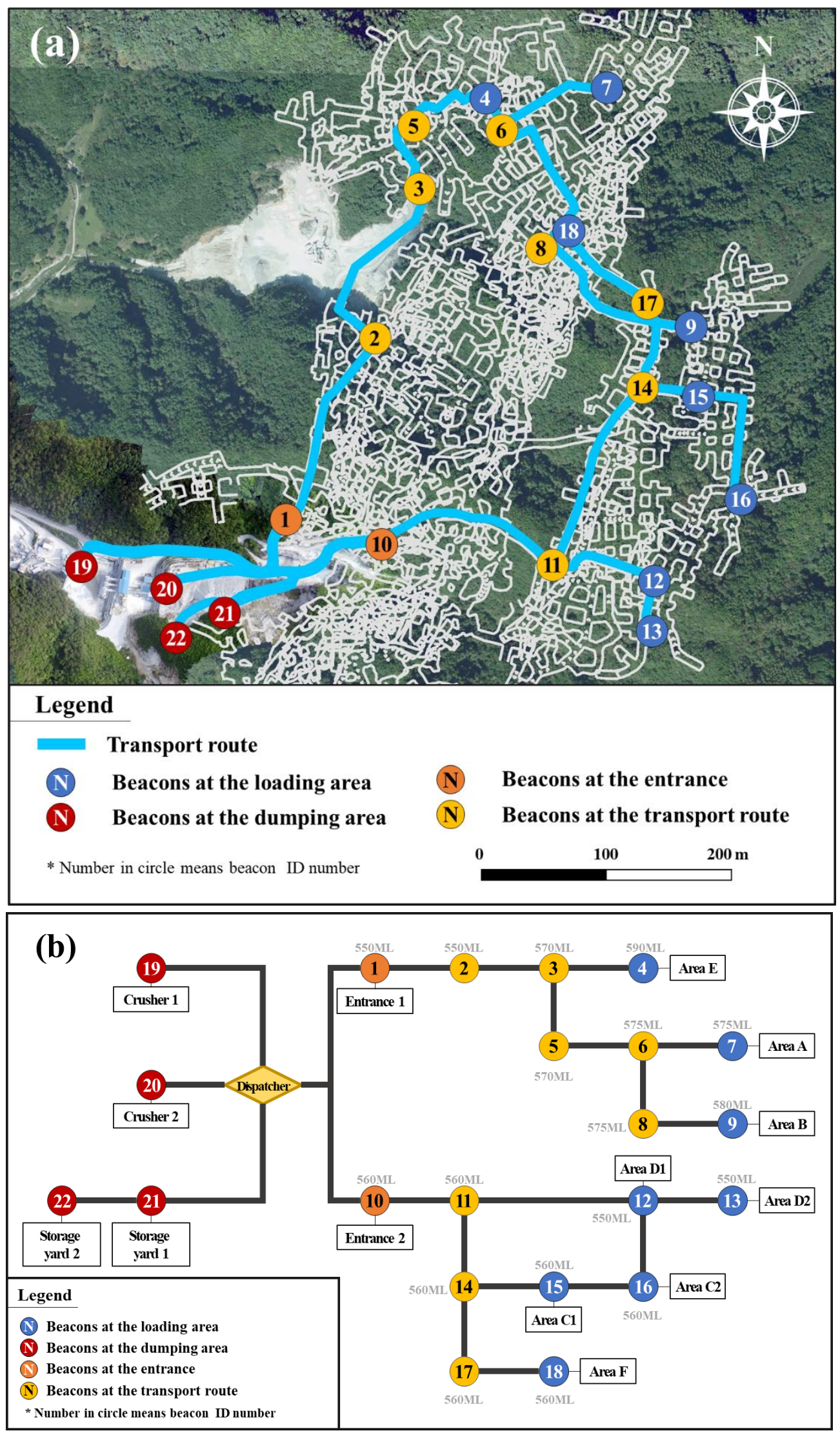

Figure 3. Transport routes between loading and unloading points and Bluetooth beacon installation points in the study area: (a) 2D maps; (b) schematic. 

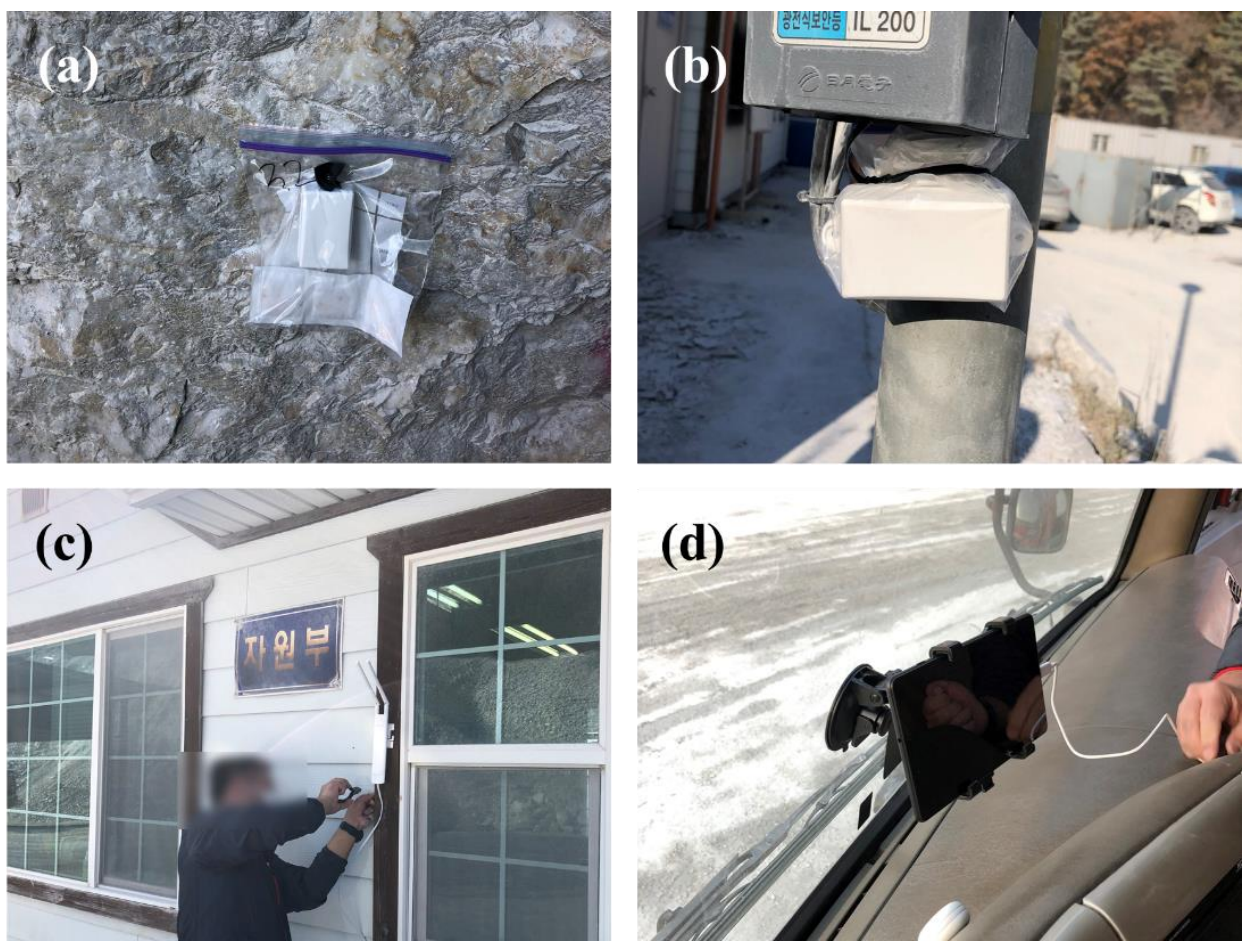

Figure 4. Examples of Bluetooth beacon (Beacon i3), Wi-Fi AP (EAP110-Outdoor) and tablet computer (Galaxy A 8.0) installed for log data collection: (a) tunnel wall on the transport route; (b) near the crusher at the crusher 2; (c) office wall near truck parking area; (d) windshield in the driver's seat of the truck.

\subsection{Development of Log Data Processing Program}

Log files stored on tablet computers during production are text data in a comma separated value format that stores items separately (with data fields being separated by commas), which can then be viewed using text editing programs (such as Notepad) or spreadsheet applications. In the log file, the time at which the tablet computer received a Bluetooth beacon signal (beacon ID, truck ID, date of production, and beacon installation point) was recorded, with one file per day being created for each production date and each truck. Data recorded in the log file were recorded in the order in which signals from the Bluetooth beacons were received. Consequently, the truck transport time between two consecutive points on its transport route could be calculated based on the time intervals of the Bluetooth beacon signals received from the two points.

The log data processing program developed in this study retrieves log files uploaded to the cloud server immediately, organizes the log data, calculates the truck transport time for each section, and outputs the statistics of the truck transport time for each section. Because the user can select the log files to be analyzed, log files can be analyzed for a specific period or truck. The program runs in Microsoft Excel and was developed using Visual Basic for Application (VBA), a macro language for Microsoft's Office applications.

When the program is executed to retrieve log files corresponding to a specific period or truck that a user wants to analyze, the program performs three-step data processing to output statistics of the truck transport time for each section (Figure 5). First, the log data of each log file recorded whenever the tablet computer detected a beacon signal is collected into a single datasheet. Next, the log data are separated by vehicle ID and the date to generate a combination of routes based on the order in which a beacon's signal is received, and the truck transport time is calculated. Finally, the statistical values of the truck transport time for the same route combination are output. Statistics output through the program include the data per route ID (comprising the beacon ID of the route origin 
and destination), the average truck transport time, standard deviation, minimum and maximum time, and percentiles (P90, P75, P25, P10) for the truck transport time.

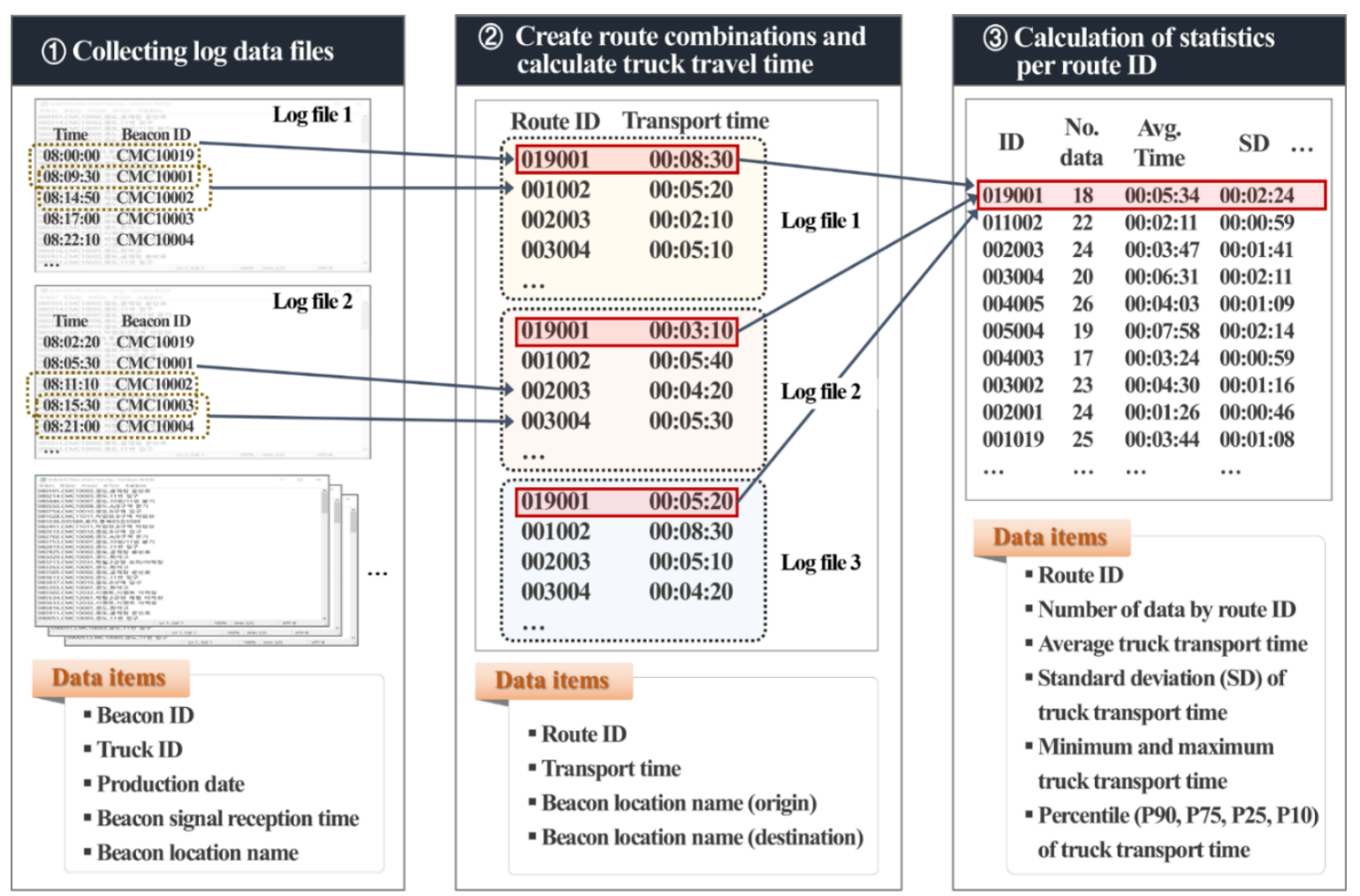

Figure 5. Conceptual diagram of the operation of the log data analysis program developed in this study.

\subsection{Truck Transport Time Data Analysis and Transport Route Diagnostic Method}

In this work, we propose a method to analyze and diagnose transport routes by examining the truck transport time for each section through a log data processing program. The analysis proceeds in three main stages: First, a log data processing program is used to calculate the statistics of the truck transport time for each section. Next, spatial analysis is conducted using the average truck transport time and standard deviation by section, and a section is selected for analysis. As for the average transport time for each section, the shorter the distance between the Bluetooth beacon installation points, the shorter the average transport time. Conversely, the longer the distance, the longer the average transport time. Therefore, a section in which the standard deviation is large means that there is a large variation in the truck transport time. Conversely, in a section where the standard deviation is small, the variation in the truck transport time is small, appearing close to the average. For this reason, when comparing the truck transport time and standard deviation for each section, there is a limitation in that the application cannot consider the differing distances for each section. Therefore, in this study, the percentage of the standard deviation for the average transport time of the truck for each section was calculated as shown in Equation (1), and the section to be analyzed was selected using this value.

$$
\frac{\text { Standard deviation }(S D) \text { of truck transport time }}{\text { Average of truck transport time }} \times 100
$$

A section in which the calculated value is large means that the standard deviation is larger than the average transport time - that is, the variation in the truck transport time is large-and the section in which the value appears small means that the variation in the truck transport time is relatively small. In this study, two sections in which the transport 
time of the truck appeared to be stable (the section with a small value) and two sections in which it appeared to be unstable (the section with a large value) were selected.

For the four selected sections, a time-series analysis was performed by dividing the $\log$ file by week; thus, the types of transport routes were classified. The type of transport route could be determined using a time-series analysis graph, in which the types of transport routes were classified into four types based on the degree of data distribution and fluctuation (Figure 6). Types 1 and 2 were sections in which the distribution of truck transport time data was large, and they were generally seen in sections where the distance between beacon installation points was long or there were loading areas or dumping areas around the transport route. In Type 1 sections, the truck transport time was expected to appear stable without a specific event during the transport operation, whereas in Type 2, the truck transport time was expected to appear unstable owing to a large distribution of time data and various events (vehicle breakdown, tunnel closure, congestion, etc.) that may have occurred during the haulage operation. Types 3 and 4 included sections in which the distribution of truck transport time data was small, generally seen where there were no loading and dumping areas on the transport route, and only ore transport operations were performed. In Type 3, the section was expected to appear stable with little fluctuation in the truck transport time. As for Type 4, the truck transport time was generally stable, but events that caused the truck transport time to rapidly increase occurred intermittently. Finally, we compared and reviewed the production logs at the site and interviewed field staff to determine why truck travel times on transport routes appeared to be stable or unstable.

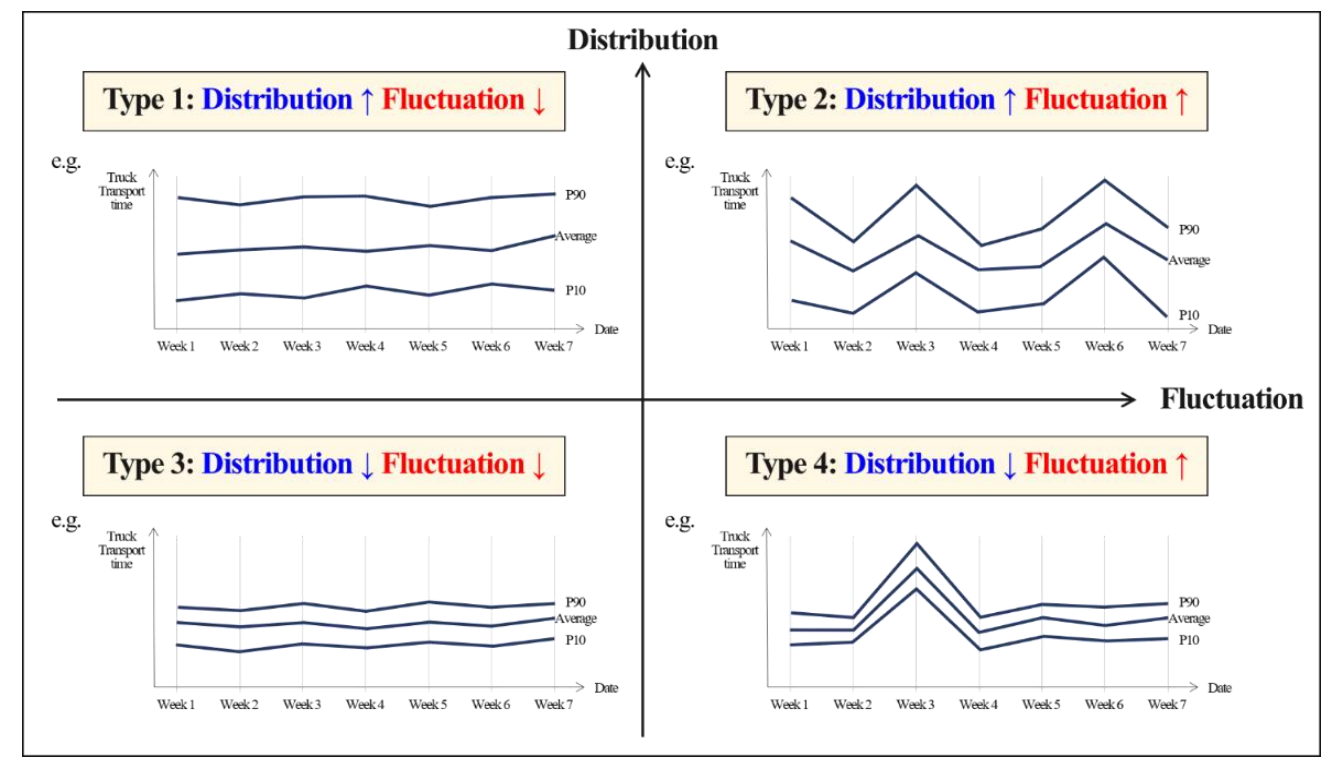

Figure 6. Classification of truck transport route types according to distribution and fluctuation of truck transport time data.

\section{Results}

Since the application of the log data collection system in the field in October 2020, log data files have been continuously collected and uploaded to the cloud server. In this study, truck transport time analysis was performed using $500 \log$ data files uploaded to the cloud server between 9 November 2020 and 21 February 2021 (15 weeks). As a result of analyzing log files uploaded from tablet computers installed on 10 trucks dispatched to haulage operations, a total of 49,876 log data were recorded; that is, the tablet computers installed on the trucks received signals from the Bluetooth beacons approximately 50,000 times. A total of 459 route combinations were automatically created using a log data processing program. However, these referred to all possible route combinations. Therefore, in this study, 46 route combinations that could be generated were analyzed by referring to the truck transport routes and the Bluetooth beacon installation schematic shown in Figure $3 b$. 
Figure 7 shows the average transport time of trucks for each section when operating with empty or loaded trucks. When an empty truck ran, it was found that the truck transport time for each section tended to increase in proportion to the distance (Figure 7a). The average transport time of trucks was relatively small in sections with short distances (beacon IDs 3-5, 12-13, and 14-15). In sections with few slopes and straight lines (beacon IDs 1-2, 2-3, 8-8, and 10-11), the average transport time of trucks was also small despite the relatively long distances. In the section from the dumping area to the entrance of the mine, the transport time was relatively large because it included the ore dumping time. Moreover, because the two sections from beacon ID 19 (crusher 1) to the entrance (beacon IDs 1 and 10) were steeply inclined sections, the truck transport time was relatively large. The truck transport time tended to be proportional to the distance, even when the truck was operating with loaded ore. However, it was confirmed that in the section where the slope of the section was high or in the section that required careful driving, the transport time was large (beacon IDs 10-19, 17-18) even if the transport distance was relatively short.
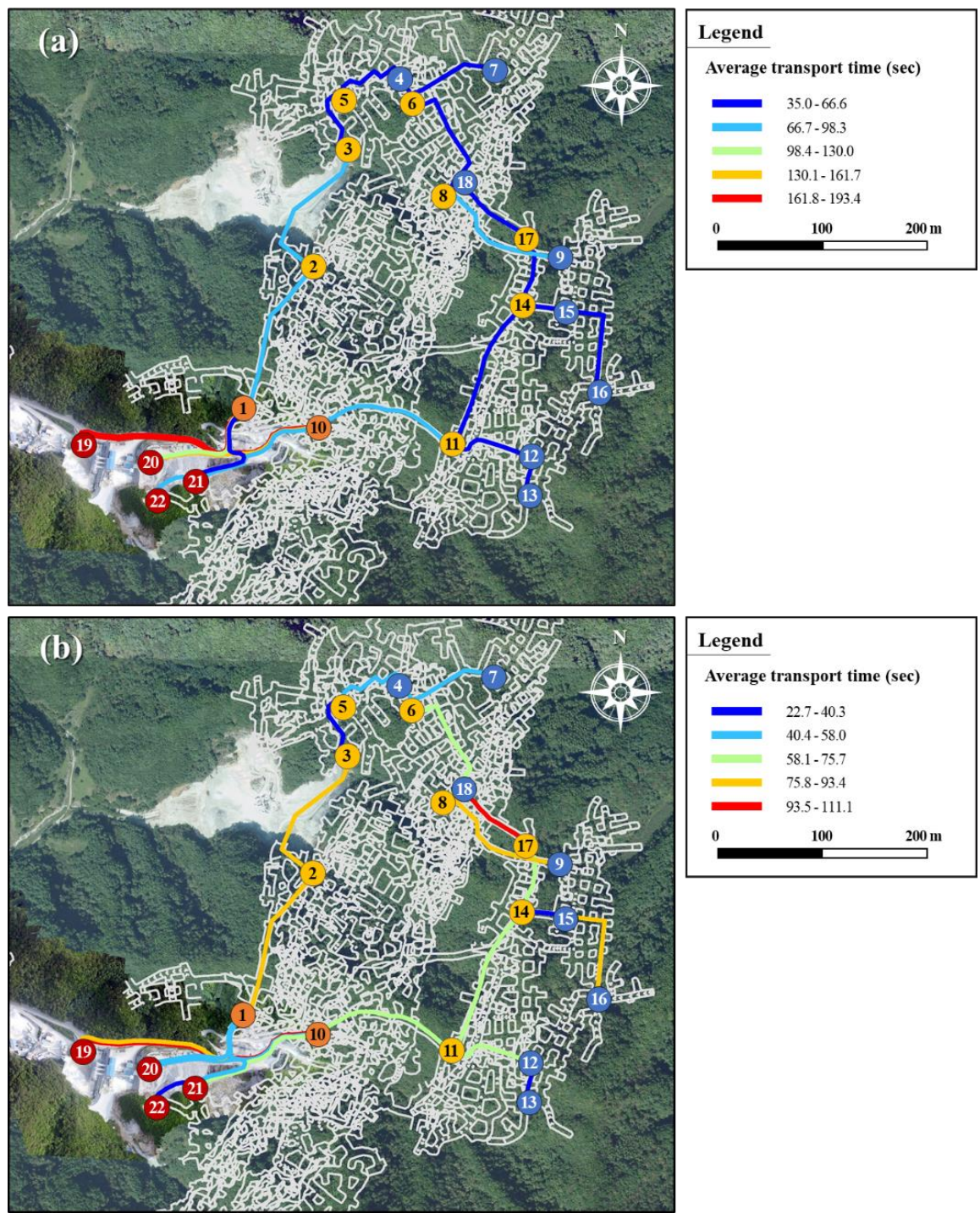

Figure 7. Average transport time of trucks by section for log data files collected over 15 weeks: (a) when operating with empty truck; (b) when operating with loaded truck.

Table 3 shows the total average truck transport time from eight loading areas to four dumping areas. The average transport time of trucks from the loading area to the dumping area (loaded truck) or from the dumping area to the loading area (empty truck) was shown 
to vary. The reason for this variation was determined to be the difference in the slope of the transport route and the weight of the truck when loading the ores. Furthermore, the closer the distance between the loading and the dumping area, the shorter the total truck transport time corresponding to one cycle (empty truck's travel-loading-loaded truck's travel-dumping). In the study area, Areas D1 and D2 showed a short total truck transport time, and Areas B, E, and F showed a long time. In general, in the case of a loaded truck, it is expected that the driving speed will be slower and the driving time will be longer because of the increase in the weight of the loaded ore. However, in most cases, the truck transport time was longer when running with an empty truck. This is because the truck transport time was excessively measured by the time that the truck waits for loading in the section close to the loading area and the time generated by congestion in the tunnel.

Table 3. Truck transport time of empty and loaded trucks from loading area to dumping area.

\begin{tabular}{|c|c|c|c|c|c|}
\hline \multirow{2}{*}{$\begin{array}{l}\text { Loading } \\
\text { Area }\end{array}$} & \multirow{2}{*}{$\underset{\text { Area }}{\text { Dumping }}$} & \multirow{2}{*}{$\begin{array}{l}\text { Placement Order of } \\
\text { Bluetooth Beacons }\end{array}$} & \multicolumn{2}{|c|}{ Average Transport Time (s) } & \multirow{2}{*}{$\begin{array}{c}\text { Total Average } \\
\text { Transport Time (s) }\end{array}$} \\
\hline & & & $\begin{array}{c}\text { Empty Truck } \\
\mathbf{D}^{*} \rightarrow \mathrm{L}^{*}\end{array}$ & $\begin{array}{c}\text { Loaded Truck } \\
\qquad \mathbf{L}^{*} \rightarrow \mathbf{D}^{*}\end{array}$ & \\
\hline \multirow{4}{*}{ Area A } & Crusher 1 & $19-1-2-3-5-6-7$ & 483.5 & 370.2 & 853.7 \\
\hline & Crusher 2 & $20-1-2-3-5-6-7$ & 415.4 & 337.7 & 753.1 \\
\hline & Storage yard 1 & $21-1-2-3-5-6-7$ & 369.1 & 337.7 & 706.8 \\
\hline & Storage yard 2 & $22-21-1-2-3-5-6-7$ & 374.0 & 367.5 & 741.5 \\
\hline \multirow{4}{*}{ Area B } & Crusher 1 & $19-1-2-3-5-6-8-9$ & 553.8 & 460.3 & 1014.1 \\
\hline & Crusher 2 & $20-1-2-3-5-6-8-9$ & 485.7 & 427.8 & 913.5 \\
\hline & Storage yard 1 & $21-1-2-3-5-6-8-9$ & 439.4 & 427.8 & 867.2 \\
\hline & Storage yard 2 & $22-21-1-2-3-5-6-8-9$ & 529.1 & 457.6 & 986.7 \\
\hline \multirow{4}{*}{ Area C1 } & Crusher 1 & 19-10-11-14-15 & 365.7 & 280.7 & 646.4 \\
\hline & Crusher 2 & 20-10-11-14-15 & 327.0 & 220.1 & 547.1 \\
\hline & Storage yard 1 & 21-10-11-14-15 & 243.3 & 246.2 & 489.5 \\
\hline & Storage yard 2 & 22-21-10-11-14-15 & 333.0 & 276.0 & 609.0 \\
\hline \multirow{4}{*}{ Area C2 } & Crusher 1 & 19-10-11-14-15-16 & 420.9 & 363.9 & 784.8 \\
\hline & Crusher 2 & $20-10-11-14-15-16$ & 382.2 & 303.3 & 685.5 \\
\hline & Storage yard 1 & 21-10-11-14-15-16 & 298.5 & 329.4 & 627.9 \\
\hline & Storage yard 2 & $22-21-10-11-14-15-16$ & 388.2 & 359.2 & 747.4 \\
\hline \multirow{4}{*}{ Area D1 } & Crusher 1 & 19-10-11-12 & 305.8 & 244.0 & 549.8 \\
\hline & Crusher 2 & $20-10-11-12$ & 267.1 & 183.4 & 450.5 \\
\hline & Storage yard 1 & $21-10-11-12$ & 183.4 & 209.5 & 392.9 \\
\hline & Storage yard 2 & $22-21-10-11-12$ & 273.1 & 239.3 & 512.4 \\
\hline \multirow{4}{*}{ Area D2 } & Crusher 1 & $19-10-11-12-13$ & 343.7 & 277.9 & 621.6 \\
\hline & Crusher 2 & $20-10-11-12-13$ & 305.0 & 217.3 & 522.3 \\
\hline & Storage yard 1 & 21-10-11-12-13 & 221.3 & 243.4 & 464.7 \\
\hline & Storage yard 2 & $22-21-10-11-12-13$ & 311.0 & 273.2 & 584.2 \\
\hline \multirow{4}{*}{ Area E } & Crusher 1 & $19-1-2-3-4$ & 521.7 & 379.6 & 901.3 \\
\hline & Crusher 2 & $20-1-2-3-4$ & 453.6 & 347.1 & 800.7 \\
\hline & Storage yard 1 & $21-1-2-3-4$ & 407.3 & 347.1 & 754.4 \\
\hline & Storage yard 2 & 22-21-1-2-3-4 & 497.0 & 376.9 & 873.9 \\
\hline \multirow{4}{*}{ Area F } & Crusher 1 & 19-10-11-14-17-18 & 414.6 & 423.4 & 838.0 \\
\hline & Crusher 2 & $20-10-11-14-17-18$ & 375.9 & 362.8 & 738.7 \\
\hline & Storage yard 1 & 21-10-11-14-17-18 & 292.2 & 388.9 & 681.1 \\
\hline & Storage yard 2 & $22-21-10-11-14-17-18$ & 381.9 & 418.7 & 800.6 \\
\hline
\end{tabular}

* D: Dumping area; * L: Loading area. 
Figure 8 shows the results of analyzing the average speed of trucks by section. It was found that the average truck speed was greatly influenced by the location and characteristics of the section during both empty and loaded operation. The truck speed tended to be higher if the section approximated a straight line, with good driver visibility. In the case of empty operation, the average speed of the truck was found to be high in beacon IDs $1-2,2-3,5-6,10-11$, and 11-14. In the case of loaded operation, the truck speed was high in the beacon IDs 10-12 and 1-20, which is believed to be because it was easy to secure visibility as the truck came out from the tunnel. Moreover, it was confirmed that the speeds were higher in the section (beacon IDs 13-12,16-15) without a loading or dumping area around the route. Conversely, in the section near a loading area where frequent congestion occurred or the section with a steep slope, the truck speed was relatively low.
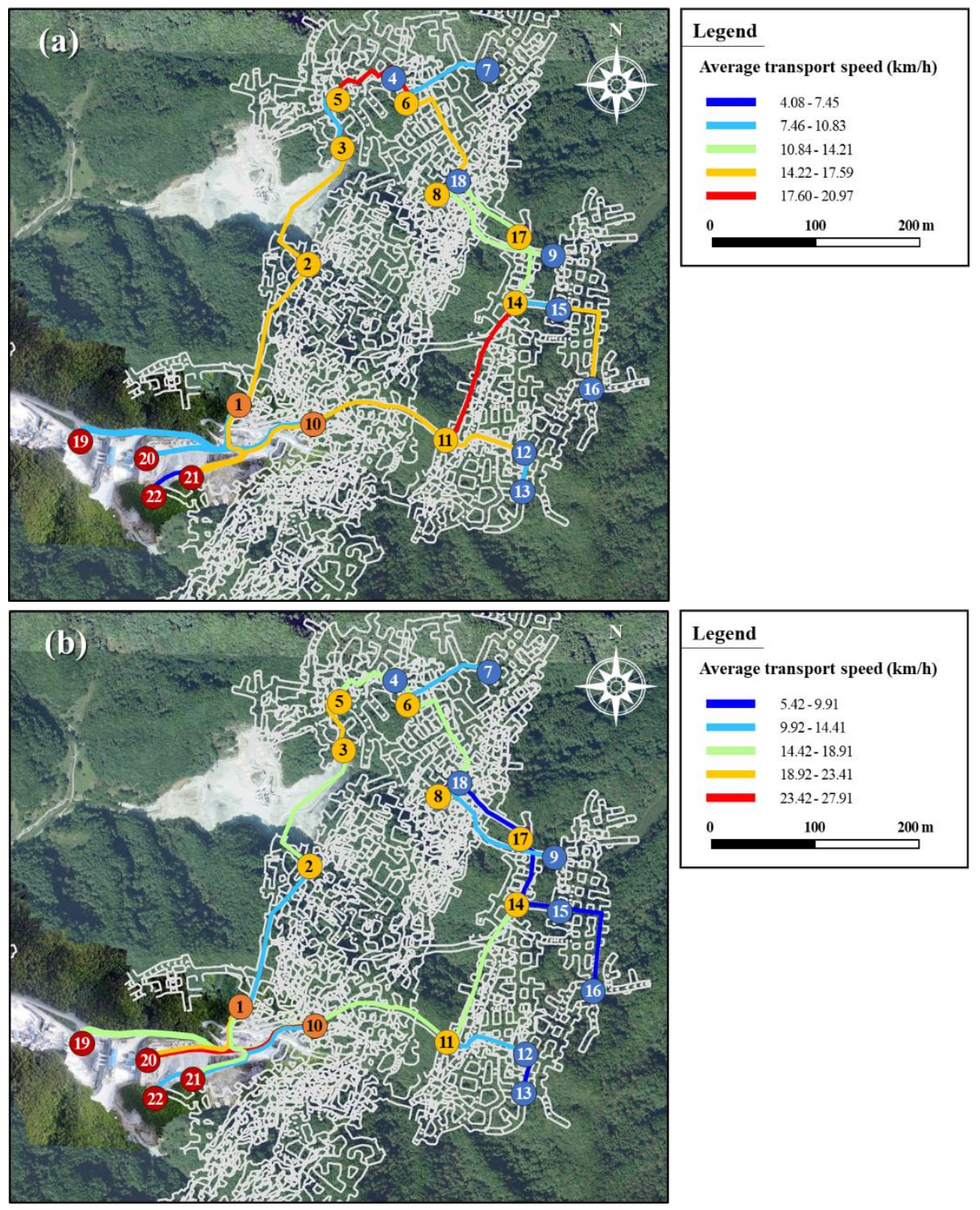

Figure 8. Average speed of trucks by section for log data files collected over 15 weeks: (a) when operating with empty truck; (b) when operating with loaded truck.

Of the 46 paths that could be combined, spatial analysis was performed using the average transport time and standard deviation of trucks for each section to select two sections in which the truck transport time appeared to be stable and a section in which the truck transport time appeared to be unstable (Figure 9). The results show that the truck transport time was stable (blue line) in 17 sections (empty truck: 9, loaded truck: 8), 
and unstable (red line) in four sections (empty truck: 2, loaded truck: 2). In the sections where there is little change in the inclination of the transport route and there are no factors that hinder the operation of the truck, the truck travel time is stable. However, when the inclination of the transport route is large or there are loading or dumping areas around the route, the truck travel time tends to be unstable. In this study, a time-series analysis was then performed on four sections (two stable sections and two unstable sections) in which the truck transport time was expected to appear stable or unstable to analyze the types and characteristics of the transport routes. The sections where the truck transport time was expected to be stable were selected from beacon IDs 19 to 1 (empty trucks) and 11 to 10 (loaded trucks), and the sections expected to be unstable were from beacon IDs 3 to 5 (empty truck) and 13 to 12 (loaded truck).
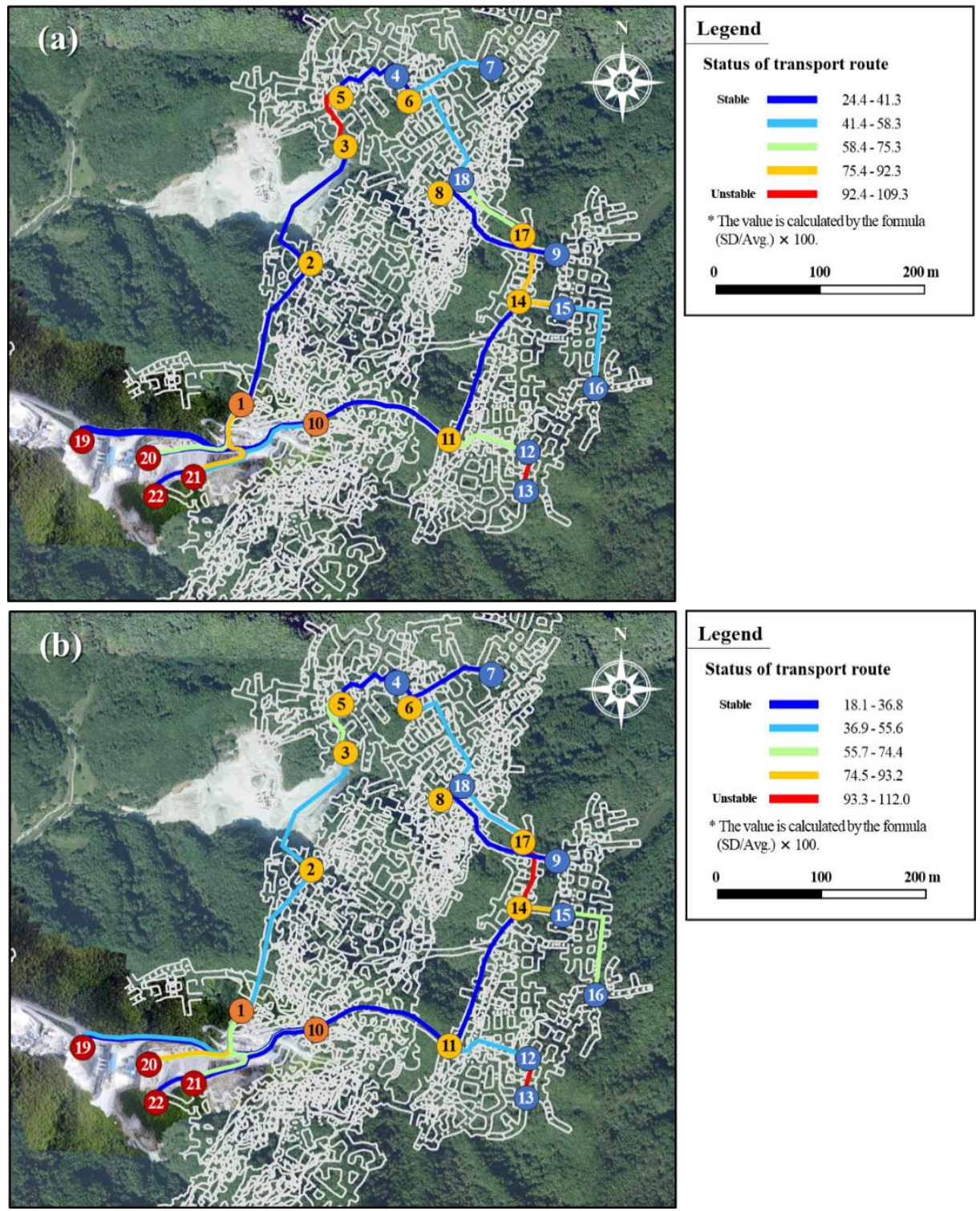

Figure 9. Results of selection of stable and unstable truck transport routes using the average and standard deviation of truck transport time: (a) when operating with empty truck; (b) when operating with loaded truck.

For the four sections selected in this study, a time-series analysis was performed by dividing the log files into weekly units, the types of transport routes then being classified (Figure 10). Figure 10a shows a large distribution of the data with little fluctuation in the 
average transport time and percentile (P90, P10) values of the trucks during the 15 weeks in which the time-series analysis was performed; that is, these transport routes could be classified as Type 1. Figure 10b is similar to Figure 10a in that there is little fluctuation in the data, but it has the characteristics of Type 3 with a small data distribution. Figure 10c shows stable truck transport time data from week 1 to week 6 , but its distribution increased from week 7 , eventually becoming unstable with severe fluctuations. Therefore, the transport route of this section could be classified as Type 2. Figure 10d shows that the truck transport time was usually a stable section, but it could be classified as Type 4 because the data fluctuated in a certain period.
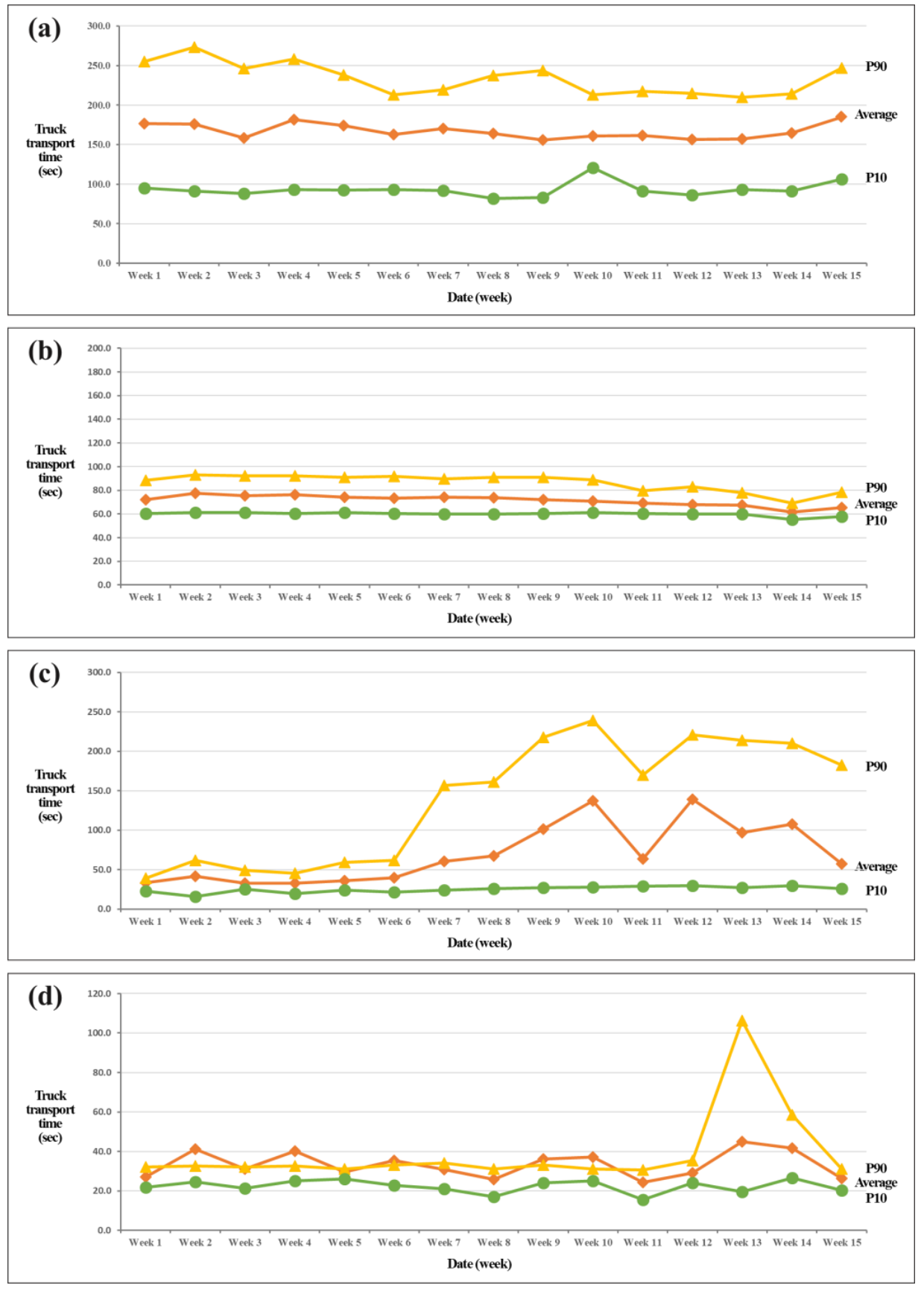

Figure 10. Time-series analysis results of stable and unstable transport routes in the study area using log data files per week (1-15 weeks): (a) beacon ID 19 to 1 (stable section); (b) beacon ID 11 to 10 (stable section); (c) beacon ID 3 to 5 (unstable section); (d) beacon ID 13 to 12 (unstable section). 
As shown in Figure 10a,b, stable transport time was realized for a main transport route where only haulage operations were performed. In these sections, the trucks were not often stopped or delayed on route. Moreover, it was found that the width of the tunnel was sufficient to allow two trucks to travel without deceleration. In particular, in the case of a section moving from beacon ID 30 to 1, the truck's transport time was found to be relatively stable because it was located outside the mine, making it easier to secure driver visibility.

In the case of Figure 10c,d, where the truck's transport time was unstable, it was found that loading or dumping areas existed near the transport route. As a result of reviewing the production logs from the site, it was confirmed that the opening of a new workplace began from the 7th week in the section, moving from beacon ID 3 to 5, and the truck transport time increased because of vehicle congestion. In the case of beacon IDs 13 to 12, the truck transport time temporarily increased during the 13th week. During this period, it was confirmed that loading operations were performed at two or more workplaces in the section.

\section{Discussion}

\subsection{Practical Use at the Underground Mine Site}

The truck transport time data, which could be collected through the log data collection system developed in this study, could be used to analyze, diagnose, and predict the truck transport routes of the mine. It was possible to determine whether the newly collected truck transport time data for a specific transport route was measured within the error range (P10 to P90) of the previously accumulated data and to diagnose whether the truck travel in the section was operating normally. Moreover, it would be possible to predict the likelihood of problems occurring in truck haulage operations. Problems that could be predicted through this include poor maintenance of mines, congestion in tunnels, poor maintenance of vehicles, and the proficiency of truck drivers.

In this study, the transport routes were diagnosed and predicted using newly acquired $\log$ data for the section of beacon IDs 13 to 12, with one showing stable truck transport times as a result of log data analysis for 15 weeks. The average transport time and percentiles $(\mathrm{P} 90, \mathrm{P} 10)$ of the truck were recalculated using the most recently collected 5 weeks of data (19 January 2021 to 21 February 2021) for the remaining 15 weeks of data. The newly collected log data were divided by date and truck, as shown in Figure 11. As a result, it was found that in the 16th week of haulage operations, two trucks operated the section and transported the limestone 42 times (truck A: 32 times, truck B: 10 times). When looking at the targeted error range of the truck transport time (P10-P90) in the corresponding section, the number of trips within the error range was found to be 27 (truck A: 20 times, truck B: 7 times). The remaining 15 times (truck A: 12 times, truck B: 3 times) were found to be out of the error range. In particular, in the case of truck A, there were two cases in which the transport time was measured to be abnormally large, as compared to the existing data.

To determine the cause of this abnormally large truck transport time, the production logs were checked, and interviews with field staff were performed. As a result, it was confirmed that vehicle congestion occurred due to the failure and maintenance of trucks in the tunnel. Problems such as the disruption or delay of trucks due to poor maintenance of the tunnel or the closing of the tunnel due to equipment failure may have increased the transport time of the truck or caused an abnormal travel pattern. Consequently, it is necessary to diagnose the condition of the transport route using the past collected data and the new collected data to predict anticipated problems. It is believed that the efficiency and productivity of truck transport operations in mines could be improved if tunnels are repaired, expanded, or opened in advance by finding sections where problems are expected to occur and if vehicles used are repaired in advance. 


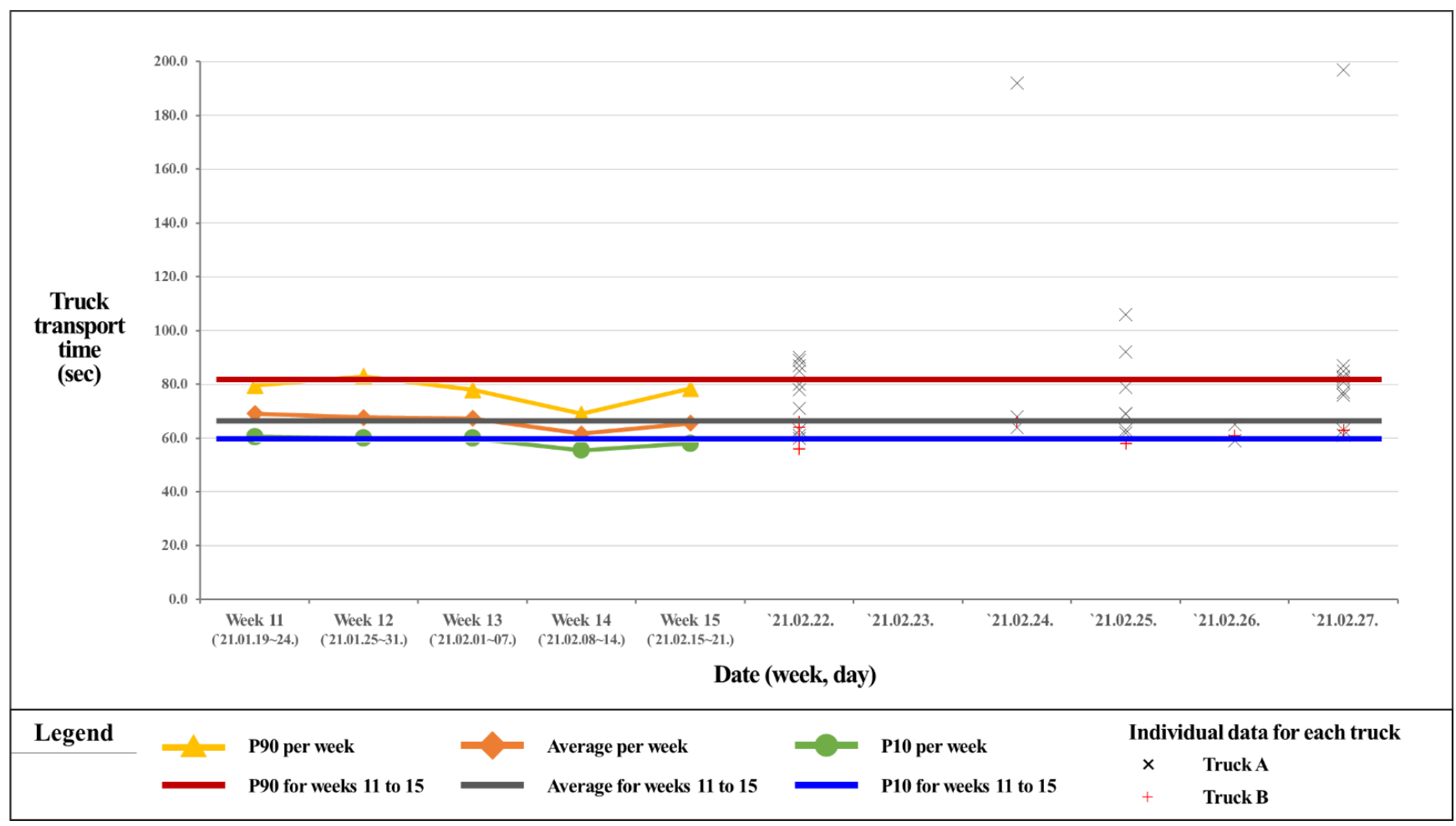

Figure 11. Comparison result of existing log data (11 to 15 weeks, '21.01.19 '21.02.21) for truck transport times and newly acquired log data (transport time per truck) at week 16 ('21.02.22 ’21.02.27).

\subsection{Implications for Simulating Truck Haulage Systems in Underground Mines}

Mine development aims to maximize production profits while investing minimal capital and operating costs over the lifetime of a mine [24]. Therefore, optimal operating methods and equipment usage strategies are required to increase the productivity of mines and minimize operating costs. In particular, efforts are being made to efficiently operate ore loading and implement material-handling operations that account for more than $50 \%$ of the total mine-operation cost [25]. Because the efficiency of the truck haulage system varies depending on the combination of the equipment used, operation patterns, and operation methods, it is necessary to operate an optimal truck haulage system that can maximize ore production and minimize the cost and time required for transport operations [26,27].

Recently, several discrete event simulation techniques [28-36] have been proposed to design an effective truck transport system and realize efficient system operation. For these simulations, a simulation algorithm is designed based on unit operations constituting the truck transport system, such as traveling, spotting, loading, dumping, and queuing [37], and the time required for unit operations is inputted as an input factor in the simulation. Existing studies have assumed that the traveling, spotting, loading, dumping, and queuing times of trucks are constant, and simulations have been performed by entering values for a specific time point or period. However, as examined in this study, it was confirmed that the characteristics and types of truck travel time differ in each transport section or period, and the distribution and fluctuation of truck transport time data by section also vary.

Therefore, to improve the prediction accuracy and confidence level of the transport system simulation, it is necessary to perform a simulation considering the uncertainty caused by the variability of the truck transport time data. The traveling time inputted for the simulation must be divided into several sections, instead of inputting one value of a single section. That is, in the case of a stable section with little variability in the transport time of the truck, the transport time can be calculated using a deterministic method and used as the simulation input data. However, in the case of an unstable section 
with large fluctuations, it would be more appropriate to determine the input value using a stochastic method.

\section{Conclusions}

In this study, we developed a system that could collect and analyze log data related to truck transport times in underground mines using Bluetooth beacons and tablet computers. We presented the results of analyzing truck transport routes by applying the system to domestic limestone underground mines. Log data related to the transport times of trucks were continuously collected through tablet computers and uploaded to a cloud server. The log data processing application developed was able to compile log data files uploaded to the cloud server into a single data file to calculate the statistics for each section of a transport route, making it easy to determine the characteristics of the truck transport time.

Through spatial analysis using the average truck transport time and standard deviation, it was possible to select the sections in which a truck's transport times were expected to be stable and sections in which they were expected to be unstable. For the selected sections, time-series analysis was performed by dividing the log data into weekly units. The transport routes were then appropriately classified. Moreover, through analysis of the production logs at a site and interviews with employees, it was possible to determine the reasons for these sections appearing stable or unstable.

The log data collection system related to truck transport times using Bluetooth beacons and tablet computers developed in this study can be used to analyze and diagnose truck transport routes in mines and improve haulage operations. The transport times of trucks may increase abnormally because of factors such as congestion in mines due to the opening of new workplaces, the centralization of workplaces based on daily production plans, inefficient equipment dispatch plans, or detours because of vehicle failures. However, by comparing and analyzing log data files continuously accumulated in the cloud and newly collected log data files, it is possible to prevent an increase in the truck transport time in advance. This will help improve the productivity and profitability of a mine, as it improves the efficiency and effectiveness of its haulage system.

The log data collection and analysis system developed in this study can only analyze $\log$ data uploaded to the cloud after production work has been completed. Consequently, it is not possible to compare and review log data collected during production using existing $\log$ data in real time. However, if a real-time comparison and review system can be established to compare existing log data with log data collected in real time during production, significant improvements in the efficiency and productivity of haulage operations can be realized. Additionally, it is believed that if the system is improved to accurately measure the time required for loading and dumping of ores, analysis and diagnosis of the entire process of truck haulage operations will be possible. Therefore, in a future study, we intend to develop a system that can compare and review the truck transport time and accurately measure the time required for loading and dumping of ores as collected through a tablet computer installed on a truck with existing data in real time.

Author Contributions: Conceptualization, Y.C.; Data curation, Y.C.; Funding acquisition, Y.C.; Investigation, S.P. and Y.C.; Methodology, S.P. and Y.C.; Project administration, Y.C.; Resources, Y.C.; Software, Y.C.; Supervision, Y.C.; Validation, S.P.; Visualization, S.P.; Writing-original draft, S.P.; Writing-review and editing, Y.C. All authors have read and agreed to the published version of the manuscript.

Funding: This work was supported by a National Research Foundation of Korea (NRF) grant funded by the Korean government (MSIT) (2021R1A2C1011216).

Institutional Review Board Statement: Not applicable.

Informed Consent Statement: Not applicable.

Data Availability Statement: Data sharing not applicable.

Conflicts of Interest: The authors declare no conflict of interest. 


\section{References}

1. Ryu, J.H.; You, Y.Y. The Fourth Industrial Revolution core technology association analysis using text mining. J. Digit. Converg. 2018, 16, 129-136. [CrossRef]

2. Choi, G.Y. Changes Brought by the 4th Industrial Revolution and Policy implication. In KISDI Premium Report; Korea Information Society Development Institute: Jincheon, Korea, 2016; Volume 16, pp. 1-37.

3. Jang, H.D. Australian Mining Transformation and Future Prospects in Response to the 4th Industrial Revolution. J. Korean Soc. Miner. Energy Resour. Eng. 2019, 56, 490-513. [CrossRef]

4. FMI. Smart Mining Market: Global Industry Analysis and Opportunity Assessment, 2015-2020, Future Market Insights Report GB-512; FMI: London, UK, 2016; 100p.

5. Choi, Y. Analysis of Patent Trend for ICT-based Underground Mine Safety Management Technology. J. Korean Soc. Miner. Energy Resour. Eng. 2018, 55, 159-164. [CrossRef]

6. Molaei, F.; Rahimi, E.; Siavoshi, H.; Afrouz, S.G.; Tenorio, V. A comprehensive review on internet of things (IoT) and its implications in the mining industry. Am. J. Appl. Sci. 2020, 13, 499-515. [CrossRef]

7. Kim, S.M. Review of Internet of Things and Open-source Hardware Technologies Use in the Mining Industry. J. Korean Soc. Miner. Energy Resour. Eng. 2019, 56, 447-456. [CrossRef]

8. Bin, S.; Xian-li, Q.; Ming-chao, F. Research of Initiative Personnel Orientation and Rescue System in Mine based on Synchronous Signal Sensei Technology. Procedia Eng. 2011, 26, 2342-2350. [CrossRef]

9. Behr, C.J.; Kumar, A.; Hancke, G.P. A smart helmet for air quality and hazardous event detection for the mining industry. In Proceedings of the 2016 IEEE International Conference on Industrial Technology (ICIT), Taipei, Taiwan, 14-17 March 2016; pp. 2026-2031.

10. Paulchamy, B.; Natarajan, C.; Wahith, A.A.; Sharan, P.M.; Vignesh, R.H. An Intelligent Helmet for Miners with Air Quality and Destructive Event Detection using Zigbee. Glob. Res. Dev. J. Eng. 2018, 3, 41-46.

11. Roja, P.; Srihari, D. Iot based smart helmet for air quality used for the mining industry. Int. J. Res. Sci. Eng. Technol. 2018, 4 514-521.

12. Mardonova, M.; Choi, Y. Review of Wearable Device Technology and Its Applications to the Mining Industry. Energies 2018, 11, 547. [CrossRef]

13. Ogallo, G.G. Development of Remote Water Quality Monitoring System Using Disruption Tolerant Networking (DTN). Ph.D. Thesis, Ohio University, Athens, OH, USA, 2016.

14. Roibal, J. New method of mine ventilation surveying data collection and analysis. In Proceedings of the New Mexico Tech Student Research Symposium 2017, Socorro, NM, USA, 19-20 April 2017.

15. Jayanthu, S.; Karthik, G.; Yadav, D.K. Current Trends in Slope Stability Monitoring in Opencast Mines Vis-À-Vis Time Domain Reflectometry. In Proceedings of the Current Practices in Mining \& Allied Industries, Keonjhar, India, 23-24 September 2017; pp. 62-70.

16. Dong, L.; Shu, W.; Sun, D.; Li, X.; Zhang, L. Pre-Alarm System Based on Real-Time Monitoring and Numerical Simulation Using Internet of Things and Cloud Computing for Tailings Dam in Mines. IEEE Access 2017, 5, 21080-21089. [CrossRef]

17. Kiziroglou, M.E.; Boyle, D.E.; Yeatman, E.M.; Cilliers, J.J. Opportunities for Sensing Systems in Mining. IEEE Trans. Industr. Inf. 2017, 13, 278-286. [CrossRef]

18. Radinovic, G.; Kim, K. Feasibilty study of RFID/Wi-Fi/BlueTooth wireless tracking system for underground mine mappingOklahoma. In Proceedings of the Incorporating Geospatial Technologies into SMCRA Business Processes 2008, Atlanta, GA, USA, 25-27 March 2008; pp. 1-34.

19. Wu, Y.; Feng, G.; Meng, Z. The study on coal mine using the Bluetooth wireless transmission. In Proceedings of the 2014 IEEE workshop on electronics, computer and applications, Ottawa, ON, Canada, 8-9 May 2014; pp. 1016-1018.

20. Baek, J.; Choi, Y. Bluetooth-Beacon-Based Underground Proximity Warning System for Preventing Collisions inside Tunnels. Appl. Sci. 2018, 8, 2271. [CrossRef]

21. Jung, J.; Choi, Y. Measuring Transport Time of Mine Equipment in an Underground Mine Using a Bluetooth Beacon System. Minerals 2017, 7, 1. [CrossRef]

22. Baek, J.; Choi, Y.; Lee, C.; Suh, J.; Lee, S. BBUNS: Bluetooth Beacon-Based Underground Navigation System to Support Mine Haulage Operations. Minerals 2017, 7, 228. [CrossRef]

23. Park, S.; Choi, Y. Bluetooth Beacon-Based Mine Production Management Application to Support Ore Haulage Operations in Underground Mines. Sustainability 2021, 13, 2281. [CrossRef]

24. Torkamani, E.; Askari-nasab, H. Verifying Short-Term Production Schedules using Truck-Shovel Simulation. In Mining Optimization Laboratory (MOL); University of Alberta: Edmonton, AB, Canada, 2012; pp. 190-205.

25. Alarie, S.; Gamache, M. Overview of Solution Strategies Used in Truck Dispatching Systems for Open Pit Mines. Int. J. Surf. Min. Reclam. Environ. 2002, 16, 59-76. [CrossRef]

26. Burt, C.N.; Caccetta, L. Equipment Selection for Surface Mining: A Review. Interfaces 2014, 44, 143-162. [CrossRef]

27. Afrapoli, A.M.; Askari-Nasab, H. Mining fleet management systems: A review of models and algorithms. Int. J. Min. Reclam. Environ. 2019, 33, 42-60. [CrossRef] 
28. Salama, A.; Greberg, J. Optimization of Truck-Loader Haulage System in an Underground Mine: A Simulation Approach using SimMine. In Proceedings of the MassMin 2012: 6th International Conference \& Exhibition on Mass Mining, Sudbury, ON, Canada, 10-14 June 2012; Canadian Institute of Mining, Metallurgy and Petroleum: Sudbury, ON, Canada, 2012; pp. 1-10.

29. Tarshizi, E.; Sturgul, J.; Ibarra, V.; Taylor, D. Simulation and animation model to boost mining efficiency and enviro-friendly in multi-pit operations. Int. J. Min. Sci. Technol. 2015, 25, 671-674. [CrossRef]

30. Soofastaei, A.; Aminossadati, S.M.; Kizil, M.S.; Knights, P. A discrete-event model to simulate the effect of truck bunching due to payload variance on cycle time, hauled mine materials and fuel consumption. Int. J. Min. Sci. Technol. 2016, 26, 745-752. [CrossRef]

31. Park, S.; Choi, Y.; Park, H. Optimization of Truck-loader Haulage Systems in an Underground Mine Using Simulation Methods. Geosyst. Eng. 2016, 19, 222-231. [CrossRef]

32. Upadhyay, S.P.; Askari-nasab, H. Simulation and optimization approach for uncertainty-based short-term planning in open pit mines. Int. J. Min. Sci. Technol. 2018, 28, 153-166. [CrossRef]

33. Samanta, B.; Sarkar, B.; Mukherjee, S.K. Selection of opencast mining equipment by a multi-criteria decision-making process. Min. Technol. 2002, 111, 136-142. [CrossRef]

34. Fadin, A.Y.F.; Moeis, A.O. Simulation-optimization truck dispatch problem using look-ahead algorithm in open pit mines. Int. J. Geomate 2017, 13, 80-86. [CrossRef]

35. Sembakutti, D.; Kumral, M.; Sasmito, A.P. Analysing equipment allocation through queuing theory and Monte-Carlo simulations in surface mining operations. Int. J. Min. Miner. Eng. 2017, 8, 56-69. [CrossRef]

36. Choi, Y.; Park, H.D.; Sunwoo, C.; Clarke, K.C. Multi-criteria evaluation and least-cost path analysis for optimal haulage routing of dump trucks in large scale open-pit mines. Int. J. Geogr. Inf. Sci. 2009, 23, 1541-1567. [CrossRef]

37. Jung, D.; Baek, J.; Choi, Y. Stochastic Predictions of Ore Production in an Underground Limestone Mine Using Different Probability Density Functions: A Comparative Study Using Big Data from ICT System. Appl. Sci. 2021, 11, 4301. [CrossRef] 